\title{
Integrated RNA-seq and sRNA-seq analysis identifies novel nitrate-responsive genes in Arabidopsis thaliana roots
}

\author{
Elena A Vidal ${ }^{1 \dagger}$, Tomás C Moyano ${ }^{1 \dagger}$, Gabriel Krouk ${ }^{2,3 \dagger}$, Manpreet S Katari ${ }^{3 \dagger}$, Milos Tanurdzic ${ }^{4,5+}$,
} W Richard McCombie ${ }^{4}$, Gloria M Coruzzi ${ }^{3^{*}}$ and Rodrigo A Gutiérrez ${ }^{1 *}$

\begin{abstract}
Background: Nitrate and other nitrogen metabolites can act as signals that regulate global gene expression in plants. Adaptive changes in plant morphology and physiology triggered by changes in nitrate availability are partly explained by these changes in gene expression. Despite several genome-wide efforts to identify nitrate-regulated genes, no comprehensive study of the Arabidopsis root transcriptome under contrasting nitrate conditions has been carried out.

Results: In this work, we employed the Illumina high throughput sequencing technology to perform an integrated analysis of the poly-A + enriched and the small RNA fractions of the Arabidopsis thaliana root transcriptome in response to nitrate treatments. Our sequencing strategy identified new nitrate-regulated genes including 40 genes not represented in the ATH1 Affymetrix GeneChip, a novel nitrate-responsive antisense transcript and a new nitrate responsive miRNA/TARGET module consisting of a novel microRNA, miR5640 and its target, AtPPC3.
\end{abstract}

Conclusions: Sequencing of small RNAs and mRNAs uncovered new genes, and enabled us to develop new hypotheses for nitrate regulation and coordination of carbon and nitrogen metabolism.

Keywords: Arabidopsis, Nitrate, RNA-seq, Roots, MicroRNA, Transcriptomics

\section{Background}

Nitrogen $(\mathrm{N})$ is an essential macronutrient and a key factor controlling plant growth and development. Nitrate is the main form of $\mathrm{N}$ available in agricultural soils [1-3]. Nitrate is taken up by the cell by specific nitrate transporters and is reduced to nitrite in the cytoplasm by nitrate reductase. Nitrite is reduced to ammonium in the plastid by nitrite reductase and is incorporated into amino acids by the glutamate synthase/glutamine synthetase cycle (GS/ GOGAT cycle). Nitrate metabolism is tightly coordinated with carbon metabolism, since carbon skeletons in the form of 2-oxoglutarate are required for ammonium assimilation $[1,4]$. One of the most striking examples of plant plasticity in response to changing environmental conditions is root

\footnotetext{
* Correspondence: gloria.coruzzi@nyu.edu; rgutierrez@bio.puc.cl

†Equal contributors

${ }^{3}$ Center for Genomics and Systems Biology, Department of Biology, New York University, New York, NY 10003, USA

${ }^{1}$ FONDAP Center for Genome Regulation. Millennium Nucleus Center for

Plant Functional Genomics, Departamento de Genética Molecular y

Microbiología, Facultad de Ciencias Biológicas, Pontificia Universidad Católica

de Chile, Santiago 8331010, Chile

Full list of author information is available at the end of the article
}

system architecture modulation by changes in nitrate availability (for reviews see [5-7]). In order to identify molecular mechanisms underlying these changes, transcriptomics analyses of the nitrate response of Arabidopsis have been performed, most of them utilizing the Affymetrix ATH1 GeneChip. Analyses with the ATH1 chip showed that nitrate is able to regulate more than 2,000 genes in roots, some of them responding as fast as 3-6 minutes after nitrate exposure [8] and including genes involved in nitrate transport, reduction and assimilation, hormone signaling pathways, transcription factors, kinases and phosphatases, among others [8-12]. However, a detailed view of the transcriptomics changes triggered by nitrate has been limited by the representation of genes in the ATH1 microarray. ATH1 contains probe sets representing approximately 21,000 genes allowing for the detection of only $71 \%$ of the genes annotated in the Arabidopsis genome v.10. Moreover, these probes do not include important regulatory elements of the genome such as small (sRNAs).

High-throughput sequencing technologies allow for quantitative determination of RNA levels and RNA

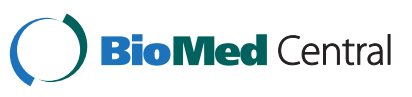


sequencing (RNA-seq) is becoming the technology of choice to investigate the transcriptome. RNA-seq offers several advantages over hybridization-based techniques like microarrays [13-18]. RNA-seq is not limited to detection of transcripts that correspond to annotated genes, thus it allows for identification of new genes. RNA sequencing can also be utilized to analyze the sRNA component of the transcriptome when libraries are prepared from low-molecular weight RNA fractions [19-24]. microRNAs (miRNAs), short interfering RNAs (siRNAs) and other types of sRNAs have been shown to play important roles in a broad range of biological processes, such as plant development and response to biotic and abiotic stresses [25-29], including plant responses to various nutrients [30-37].

In plants, the sRNA transcriptome is primarily composed of 23-24 nt siRNAs and 21-22 nt miRNAs [36,38,39]. Since miRNA precursors have distinctive secondary structures, many bioinformatics programs have been developed to predict new miRNAs based on sequencing of a sRNA in a library and inspection of the genome sequence containing this sequence for putative miRNA precursors [40-42]. Combination of deep sequencing approaches and bioinformatics predictions have identified 19,724 miRNAs related sequences across different phyla out of which 266 correspond to Arabidopsis miRNAs in miRBase v.17 [43].

miRNA regulation of nitrate-responsive genes has been shown to be a key mechanism of plant responses coordinating nitrate availability and root developmental responses. miR167 is down-regulated by nitrate treatments in pericycle cells and this leads to an induction of its target, the auxin response factor ARF8 [44]. Regulation of ARF8 by miR167 causes a change in the ratio of initiating and emerging lateral roots in response to nitrate [44]. Another nitrate regulatory module, consisting of miR393 and the AFB3 auxin receptor has been shown to control root system architecture in response to external and internal nitrate availability [37]. Microarray analysis suggests that other miRNAs can be involved in root responses to nitrate, since several miRNA targets are regulated by nitrate [45].

In this paper, we used Illumina sequencing technology to characterize the poly-A + and sRNA component of nitrate- and control-treated Arabidopsis roots to identify new nitrate-responsive genes. Using bioinformatics analysis of our libraries and miRNA prediction algorithms we were able to find new root expressed genes including new mRNAs and miRNAs. We discovered a new miRNA/target module that might act as an integrator of $\mathrm{N}$ and carbon metabolism in Arabidopsis roots.

\section{Results}

Deep sequence analysis of the root transcriptome In order to determine poly-A + and sRNA expression of Arabidopsis roots and their changes in response to nitrate, we grew plants in hydroponic nitrate-free medium with $0.5 \mathrm{mM}$ ammonium succinate as the only $\mathrm{N}$-source for two weeks and treated them with $5 \mathrm{mM}$ $\mathrm{KNO}_{3}$, or $5 \mathrm{mM} \mathrm{KCl}$ as control, for 2 hours. These experimental conditions have been previously shown to elicit robust gene expression responses to nitrate $[10,44,45]$. Total RNA from two independent sets of plants (biological replicates) was extracted from roots, and poly-A + enriched and sRNA fractions were used to construct libraries for Illumina sequencing (see Methods for details). The sequencing yielded $\sim 5$ to 8 million 35 bp long (sRNA libraries) or $50 \mathrm{bp}$ long (poly-A + libraries) raw reads per sample library. After quality control filtering and trimming adaptor sequences (see Methods), the reads were mapped to the Arabidopsis thaliana genome using the Arabidopsis genome annotation available at The Arabidopsis Information Resource (TAIR) v.10 (www.arabidopsis.org). Approximately two thirds of the total Illumina reads perfectly matched the genome and were used for further analysis (Additional file 1).

Analysis of the size distribution of sequences in the sRNA libraries showed that 21 nt long RNA molecules were the most abundant followed by 24 nt long sequences (Additional file 2). The pattern of sRNA sizes reflects a typical population of sRNAs with abundant miRNAs and tasiRNA (21-22 nt) and siRNAs (23-24 nt) (Additional file 2). However, we did not find accumulation of tRNA fragments as described in roots of phosphate-starved plants [38] or nitrate-starved seedlings [33]. We did not observe any obvious effect of nitrate provision on RNA size distribution (Additional file 2), suggesting that nitrate treatments under our experimental conditions do not have a global effect on sRNA population structure. Next, valid sequences were classified according to the genomic regions they match. Most sRNA sequences matched intergenic regions $(8,415,076$ sequences, 50\%), followed by miRNA $(3,189,443$ sequences, $19 \%)$ and rRNA genes (2,469,734 sequences, $14 \%$ of the total valid reads) (Figure 1A). We were able to detect 142 distinct mature Arabidopsis miRNA sequences, corresponding to 98 different miRNA families, according to the miRBase database v.17 (www.mirbase.org) (Additional file 3). The number of miRNA sequences identified represents $66.7 \%$ of the 212 miRNAs reported in miRBase v.17, indicating that a considerable proportion of known miRNAs are expressed in the root organ. This number greatly exceeds the previously reported number of miRNAs expressed in roots, that indicated expressed miRNAs are less than $40 \%$ of the annotated total miRNAs [36,46]. We were also able to identify sequences corresponding to trans-acting siRNAs (ta-siRNA), including ta-siRNAs arising from the TAS1, TAS2 and TAS3 genes (Additional file 3). It has recently been shown that a significant number of miRNAs have specific root developmental zone or root cell type 


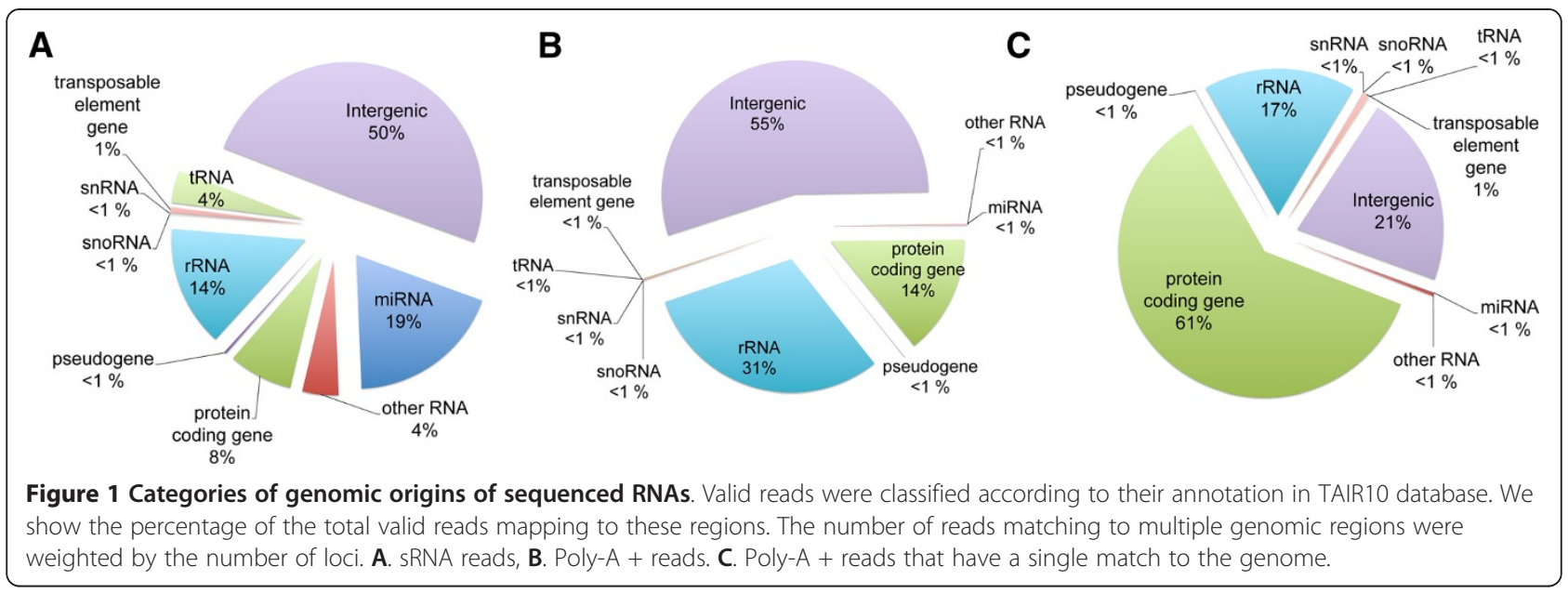

expression profiles [47]. Most root miRNAs showed low expression levels under our experimental conditions (Additional file 3), suggesting developmental control or expression in specific cell-types of the Arabidopsis root.

For Illumina libraries made from poly-A + RNA, a considerable amount of sequences map to intergenic regions $(9,542,618$ sequences, $55 \%$ of the reads) (Figure 1B). Inspection of sequences matching intergenic regions showed that most of them arise from telomeric or centromeric regions. Transcription from intergenic zones has been reported in previous high-throughput sequencing and tiling array experiments [48-51]. When we considered sequences with a unique match to the genome, only 732,226 sequences (22\%) mapped to intergenic regions (Figure 1C). A high proportion of these sequences is supported by Arabidopsis ESTs or cDNAs $(710,814$ sequences, $97 \%)$ obtained from TAIR.

As shown in Additional file 4, most of these sequences are located near the $5^{\prime}$ or $3^{\prime}$ of annotated genes. We found sequences matching intergenic regions from poly$\mathrm{A}+$ enriched libraries matching the same strand as annotated genes (Additional file $4 \mathrm{~A}, \mathrm{C}$ ). Interestingly, we also found sequences near annotated genes in antisense orientation (Additional file 4 B,D). These could represent novel transcripts that could have a role in controlling the expression of corresponding genes.

Reads matching protein coding genes $(2,094,509$ sequences) represent $\sim 60 \%$ of the unique reads in poly- $\mathrm{A}+\mathrm{li}$ braries (Figure 1C). The number of expressed protein coding genes detected unambiguously (19,979 protein coding genes) represents $73 \%$ of the total annotated in the Arabidopsis genome. Similar to sRNAs, a considerable proportion of genes are expressed in a cell-specific manner [52,53], thus some of the low-expressed transcripts detected under our experimental conditions might be developmentally controlled and/or expressed in specific cell-types of the root.

To date, most transcriptomics studies on the root nitrate response have been performed using the Affymetrix
ATH1 GeneChip [8-11,44,45,54]. In order to determine how our sequencing data compares with data obtained with the Affymetrix ATH1 GeneChip, we used the same RNA samples for Illumina library preparation and ATH1 microarray hybridization. We used the affy package library from Bioconductor (www.bioconductor.org) to determine the number of present calls in the ATH1 microarrays as a measure of gene detection. We were able to find 13,964 probes with a present call, approximately $67 \%$ of the gene specific probes that are present in the ATH1 microarray (Additional file 5). The Illumina sequencing data detected 13,411 of these genes $(96 \%$, at least one read matching the gene) and 3,022 annotated elements that were called absent in the ATH1 array. We found that these 3,022 elements had low expression values when compared with the 13,411 Illumina-detected elements that had present calls in Affymetrix (Additional file 6A,B). Additionally, Illumina was able to detect 4,215 elements that had no probe on the ATH1 microarray (Additional file 5).

In order to determine how data on nitrate-responsive genes obtained with RNA-seq and Affymetrix ATH1 chips correlated, we calculated the correlation between the $\mathrm{KNO}_{3} / \mathrm{KCl}$ ratio for RMA normalized Affymetrix gene expression and the $\mathrm{KNO}_{3} / \mathrm{KCl}$ ratio obtained for normalized libraries at different average gene coverages (AGCs). We defined AGC as the number of reads matching a gene multiplied by read length and divided by gene length. We found correlation between $\mathrm{KNO}_{3} / \mathrm{KCl}$ ratios increase hyperbolically as average gene coverage increases (Additional file 7). This indicates correlation between the two techniques depends on gene expression levels. We found excellent correlation $\left(r^{2} \geq 0.9\right)$ between RNA-seq and ATH1 arrays when gene coverage was 0.8 or higher (reads matching the gene represent $80 \%$ or more of the gene length) (Additional file 7). These results highlight the potential of the sequencing strategy to identify novel nitrate-responsive genes in Arabidopsis roots. 
Deep sequencing reveals a new nitrate-responsive component of the arabidopsis root transcriptome In order to identify known miRNAs that are N-regulated under our experimental $\mathrm{N}$-treatment conditions, we used the DESeq package in $\mathrm{R}$ to analyze digital gene expression in the RNA-sequencing data [55]. Replicates were used independently for statistical analysis of gene expression. Surprisingly, we were not able to identify known miRNAs (reported in miRBase v17) regulated by nitrate in roots based on our RNA-sequencing data. In order to distinguish between a technical and biological explanation for this result, we calculated an RNA rarefaction curve considering increasing number of random sequences from our sRNA libraries and the number of different sequences that could be determined from each sample (Figure 2A). We found that even when considering the total number of sequences available in our experiments, almost 17 million reads, we were far from saturation. This analysis indicates that most molecules in our sRNA libraries were sequenced only a few times, making it difficult to obtain accurate quantitative results. Using the same RNA samples and quantitative real time PCR, we were able to corroborate induction of miR393 (Figure 2B), a miRNA previously identified as nitrate responsive [37]. This result indicates that a significantly higher depth of sequencing than the current standards
$[33,34,36,38]$ is required for quantitative comparison of the sRNA fraction of the Arabidopsis transcriptome. In contrast, when quantifying mRNAs a considerably lower number of sequences is required to reach saturation (Figure $2 \mathrm{C}$ ).

Among the poly-A + sequences, we found 505 regulated genes, considering only sense sequences that have a unique match to known genes. From these genes, 392 were induced and 113 were repressed by the nitrate treatment (Additional file 8). Regulated genes had an overrepresentation of genes belonging to the "nitrate response", "nitrate transport", "nitrate metabolic process", "nitrate assimilation", "nitrogen cycle metabolic process" and "cellular nitrogen compound biosynthetic process" Gene Ontology annotation, indicating that RNA-seq was successful for identifying nitrate responsive genes. Among these nitrateregulated genes, we found 40 protein coding genes without probes in the ATH1 GeneChip (Table 1). We selected eight genes and validated them using real time quantitative reverse transcription polymerase chain reaction (RT-qPCR) (Additional file 9). Among the new nitrate-responsive genes, we found transcription factors and components of signaling cascades such as a $\gamma$ subunit of the heterotrimeric G protein, AGG2. These genes may represent novel targets in the nitrate regulatory pathways in plants.
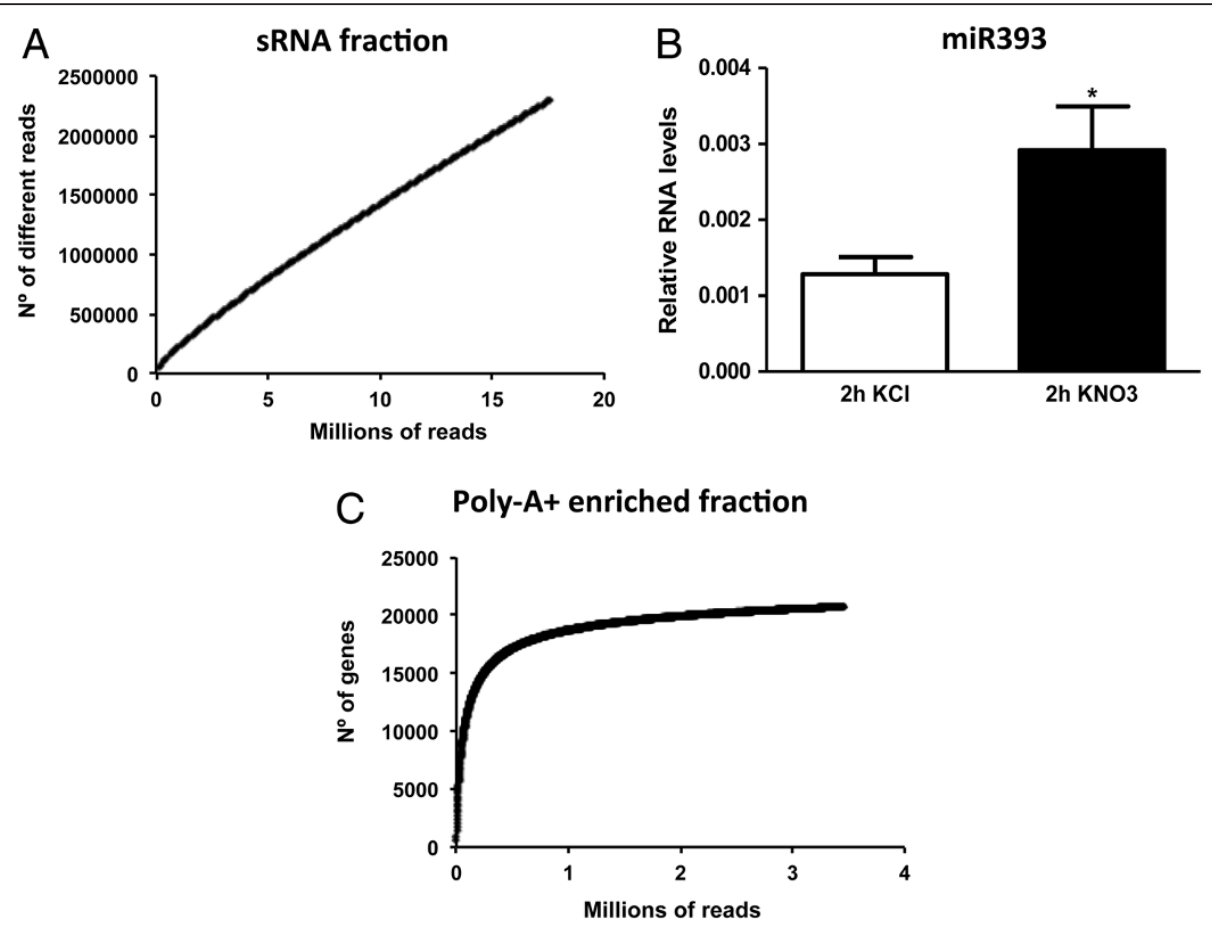

Figure 2 Analysis of the diversity of sequences suggests that a higher depth of sequencing is required for quantitative results for sRNA libraries. A.Rarefaction curve represents the number of different reads found at the indicated number of reads. The $Y$ axis represents the number of different sequences that could be determined from each sample and the $X$ axis represent the number of random sequences from our sRNA libraries. B. miR393 is regulated by nitrate in qRT-PCR experiments. We show results for three biological replicates. We show standard errors for each bar. The asterisk indicates means that differ significantly $(p<0.05)$. C. Rarefaction curve of unique reads that match annotated genes from poly-A + libraries. 
Table 1 Illumina sequencing of poly-A + RNA enriched fraction identifies new nitrate responsive genes

\begin{tabular}{|c|c|c|}
\hline AGI identifier & Description & $\log _{2}\left(\mathrm{KNO}_{3} / \mathrm{KCl}\right)$ \\
\hline AT5G63160 & BT1, BTB and TAZ domain protein 1 & 5.2 \\
\hline AT1G11655 & Unknown protein & 4.3 \\
\hline AT5G65030 & Unknown protein & 4.2 \\
\hline AT1G70260 & nodulin MtN21 /EamA-like transporter family protein & 4.0 \\
\hline AT2G33550 & Homeodomain-like superfamily protein & 3.7 \\
\hline AT1G68238 & Unknown protein & 3.7 \\
\hline AT4G34419 & Unknown protein & 3.6 \\
\hline AT1G02030 & $\mathrm{C} 2 \mathrm{H} 2$-like zinc finger protein & 3.1 \\
\hline AT4G34800 & SAUR-like auxin-responsive protein family & 3.0 \\
\hline AT5G03330 & Cysteine proteinases superfamily protein & 2.9 \\
\hline AT1G60050 & Nodulin MtN21 /EamA-like transporter family protein & 2.9 \\
\hline AT2G45760 & BAL, BAP2, BON association protein 2 & 2.8 \\
\hline AT1G70800 & Calcium-dependent lipid-binding (CaLB domain) family protein & 2.8 \\
\hline AT4G29905 & Unknown protein & 2.7 \\
\hline AT3G22942 & AGG2, G-protein gamma subunit 2 & 2.2 \\
\hline AT1G23149 & CPuORF29, conserved peptide upstream open reading frame 29 & 2.2 \\
\hline AT1G23150 & Unknown protein & 2.2 \\
\hline AT5G65980 & Auxin efflux carrier family protein & 2.2 \\
\hline AT3G14260 & Protein of Unknown function (DUF567) & 2.1 \\
\hline AT3G48180 & Unknown protein & 2.1 \\
\hline AT3G25717 & DVL6, RTFL16, ROTUNDIFOLIA like 16 & 2.1 \\
\hline AT2G41440 & Unknown protein & 2.1 \\
\hline AT1G13245 & DVL4, RTFL17, ROTUNDIFOLIA like 17 & 2.0 \\
\hline AT1G68825 & DVL5, RTFL15, ROTUNDIFOLIA like 15 & 2.0 \\
\hline AT5G58320 & Kinase interacting (KIP1-like) family protein & 2.0 \\
\hline AT3G29034 & Unknown protein & 1.9 \\
\hline AT1G22882 & Galactose-binding protein & 1.6 \\
\hline AT4G04745 & Unknown protein & 1.6 \\
\hline AT4G09180 & basic helix-loop-helix (bHLH) DNA-binding superfamily protein & 1.3 \\
\hline AT1G45249 & ABF2, abscisic acid responsive elements-binding factor 2 & 1.3 \\
\hline AT5G38200 & Class I glutamine amidotransferase-like superfamily protein & 1.2 \\
\hline AT2G18193 & P-loop containing nucleoside triphosphate hydrolases superfamily protein & 1.2 \\
\hline AT5G10200 & ARM-repeat/Tetratricopeptide repeat (TPR)-like protein & 1.2 \\
\hline AT5G52882 & P-loop containing nucleoside triphosphate hydrolases superfamily protein & 0.9 \\
\hline AT2G31141 & Unknown protein & 0.8 \\
\hline AT3G48340 & Cysteine proteinases superfamily protein & -1.0 \\
\hline AT2G23790 & Protein of Unknown function (DUF607) & -1.2 \\
\hline AT1G52120 & Mannose-binding lectin superfamily protein & -1.5 \\
\hline AT4G39795 & Protein of Unknown function (DUF581) & -1.9 \\
\hline AT3G06550 & O-acetyltransferase family protein & -2.0 \\
\hline
\end{tabular}

Reads were mapped to the Arabidopsis genome and regulated genes were determined using DESeq. We identified protein coding genes that were not represented on the Affymetrix ATH1 microarray. We show the $\log _{2}\left(\mathrm{KNO}_{3} / \mathrm{KCl}\right)$ value for 2 biological replicates.

\section{Prediction of new genes}

In order to identify regions of the Arabidopsis genome that could encode new genes expressed under our experimental nitrate-treatment conditions, we searched for clusters of sequences that match the genome uniquely in regions without annotation (see Methods). These clusters could overlap annotated genes but in anti-sense orientation. Average exon length in the Arabidopsis genome (TAIRv10) is $298 \mathrm{nt}$, therefore we only considered clusters of $300 \mathrm{nt}$ or more. We found 17 clusters with 
these criteria (Additional file 10), 4 of which were located in the complementary strand of annotated genes and might represent natural antisense transcripts (NATs). Two clusters have been previously reported as cis-NATs in an analysis of Arabidopsis full-length cDNAs, At5g49440 and At3g19380 [56]. We found that one of the 17 clusters was induced by nitrate treatments. We labeled this cluster TCP23as as it is antisense to the TCP transcription factor TCP23 (At1g35560) (Figure 3A). We also found sRNAs matching the same region both in sense and antisense orientation (Figure 3B), however we did not find a correlation between their expression and TCP23as regulation by nitrate, suggesting these sequences most likely represent degradation products of TCP23 and
TCP23as. TCP23 was found not to be regulated by nitrate in our RNA-sequencing data (Additional file 5). In order to validate expression of this putative antisense transcript, we reverse-transcribed root RNA using strand-specific primers for TCP23 and for its antisense transcript and performed PCR with gene specific primers. As shown in Figure 3C, both TCP23 and TCP23as are expressed in roots, but only TCP23as is induced by the nitrate treatment. Our data suggest TCP23as could represent a novel nitrate-regulated transcript that might regulate TCP23 expression at the transcriptional or post-transcriptional level. Given the low expression levels of TCP23 in whole root sample, it is likely that its regulation by TCP23as occurs only in a subset of root cells.
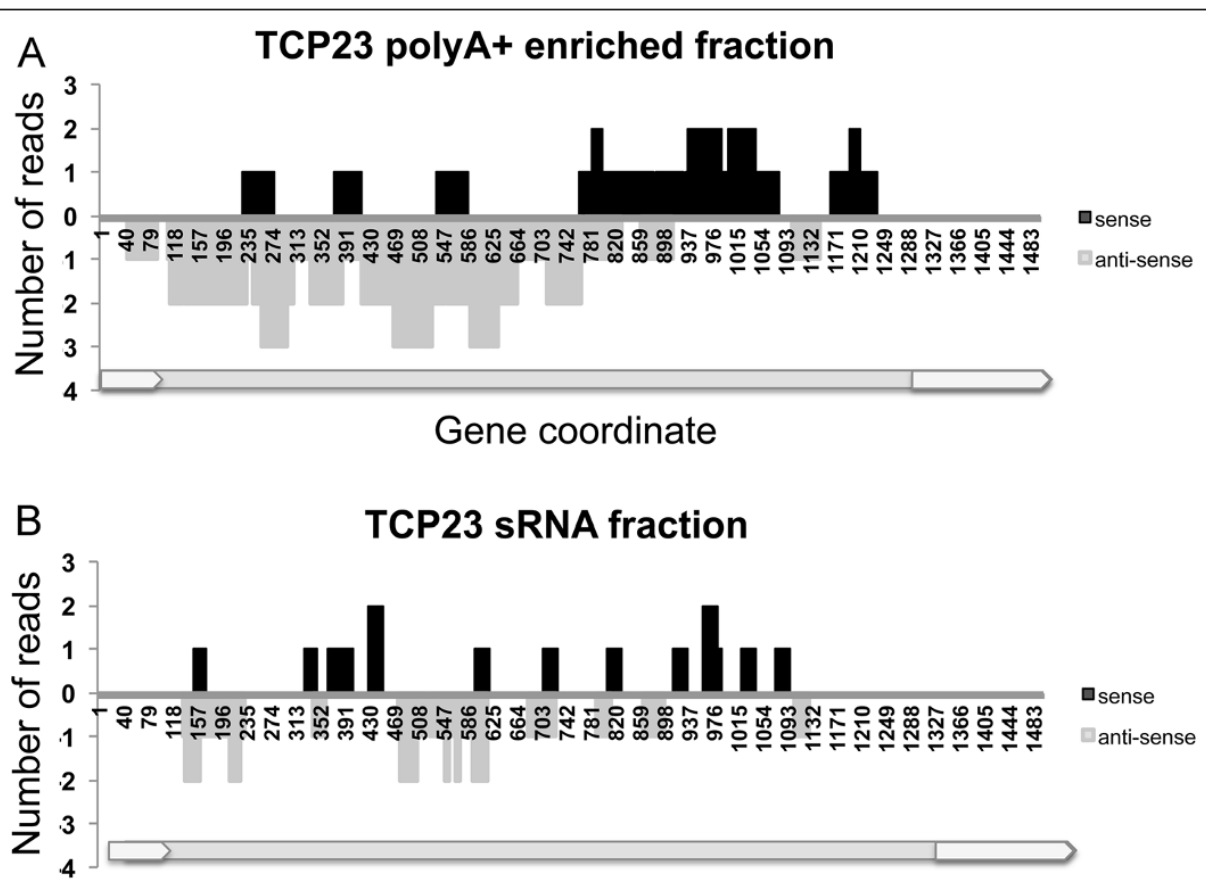

Gene coordinate

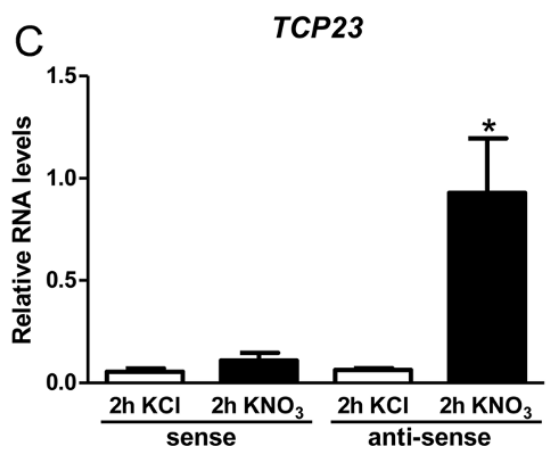

Figure 3 TCP23as is a novel nitrate-regulated gene that is anti-sense to TCP23. A. We represent RNA poly-A + transcripts mapping the TCP23 (AT1G35560) region. The black and grey bars represent reads sense or antisense to AT1G35560 respectively. We show the gene structure of TCP23 in gray. Gray represents 5'UTR and $3^{\prime} \mathrm{UTR}$ and dark gray represents the coding region. B. We represent sRNA transcripts mapping the TCP23 locus similar to panel A. C. CDNA was prepared using strand-specific primers for TCP23 and TCP23as. We quantified relative RNA levels of both transcripts using RT-qPCR. We show the results of three biological replicates and standard error. 


\section{Prediction of novel miRNA genes}

Numerous approaches have been utilized to predict and discover miRNAs [57,58]. However, few experiments have been performed under contrasting $\mathrm{N}$ nutrient conditions $[33,34,36]$. To generate a list of putative new miRNAs that may be expressed under our experimental conditions, we used the miRNA gene prediction tool available in the University of East Anglia (UEA) sRNA toolkit, miRCat (http://srna-tools.cmp.uea.ac.uk) [59]. We chose this prediction tool because it is optimized for the identification of plant miRNA hairpins, and it has been trained and tested with published Arabidopsis thaliana high-throughput sRNA sequence data. We used as input for miRCat the filtered sRNA sequences obtained from our 4 sRNA libraries. miRCat was able to predict 123 mature miRNA sequences corresponding to $87 \%$ of the known miRNAs identified in our samples, indicating that the prediction algorithms implemented in miRCat are highly efficient in identifying plant miRNAs. The miRCat program was able to predict 51 new miRNA sequences when compared with miRBase v17 (Table 2). From these 51 new miRNA sequences our studies uncovered, 12 were recently cross-validated by other groups, suggesting the veracity of our results [47,60-63]. 21 putative new miRNA sequences were found in intergenic regions, likely representing new transcriptional units (Table 2). 10 miRNA sequences were found inside introns and 2 were found in the 5'UTR of protein coding genes suggesting they are transcribed along with the gene they overlap and 1 miRNA was found in a pseudogene (Table 2). 17 new miRNA sequences were located inside the region coding for the stem loop of known miRNAs (Table 2). Sequences that map onto miRNA precursors and that do not correspond to the mature miRNA or miRNA* sequences have been previously reported in Arabidopsis and are potentially functional miRNAs that are generated by the miRNA pathway $[64,65]$. All these new miRNAs have low expression levels, most of them being sequenced less than 50 times in our libraries, which probably explains why they have not been reported previously.

\section{A novel nitrate-responsive miRNA/target regulatory module (AtPPC3/miR5640)}

In order to further characterize the role of the novel miRNAs in the root nitrate response, we predicted target genes for new miRNAs sequenced in our libraries using the target prediction tool Target finder from the UEA sRNA toolkit, (Additional file 11). The program is based on a set of rules determined specifically for plant miRNA/TARGET interactions [66,67]. We looked in the target list for genes that could be related to $\mathrm{N}$ metabolism or to root growth regulation and that were either induced or repressed by nitrate based on our Illumina results. One of the predicted targets was the transcript for PHOSPHOENOL PYRUVATE CARBOXYLASE 3 (AtPPC3, At3g14940) (Additional file 11), an enzyme that catalyzes $\mathrm{CO}_{2}$ incorporation with phosphoenol pyruvate to form oxaloacetate [68]. AtPPC3 is induced in roots after nitrate treatment based on our sequencing data (Additional file 8). The miRNA predicted to target AtPPC3 has recently been reported as miR5640 [47]. miR5640 has been shown to be expressed in Arabidopsis primary root in the apical half of the meristematic zone (early meristematic zone), the elongation zone, and the maturation zone, according to sequencing data, but no additional validation on its expression or additional characterization of its function or target prediction has been performed [47]. In order to validate miR5640 as a bona fide miRNA, we confirmed its expression and expression of its precursor in roots using RT-qPCR. In addition, miR5640 precursor accumulated in the DCL1 (dcl1-9) mutant plants (Figure 4A), indicating that miR5640 precursor is processed by DCL1 as most miRNA precursors [69]. In order to experimentally confirm that AtPPC3 is a miR5640 target and to map the miR5640 cleavage site, we performed a modified RLMRACE procedure [70]. We were able to detect and clone an amplification product corresponding to the expected size of a miR5640-cleaved AtPPC3 fragment. It has been described that cleavage of the target transcripts occurs near the middle of the base-pairing interaction [71,72]. As shown in Figure 4B, 30 out of 32 clones sequenced had a cleavage site inside the miRNA complementary sequence, between the $8^{\text {th }}$ and $9^{\text {th }}$ complementary bases from the miRNA $5^{\prime}$ end. This result suggests that AtPPC3 is a target of miR5640 and further corroborates miR5640 as a bona fide miRNA. Based on our sequencing data, we did not find differential expression of miR5640 2 hours after nitrate treatment, although AtPPC3 is induced by this treatment. In order to determine if miR5640/AtPPC3 could represent a nitrateresponsive miRNA/TARGET module, we analyzed the nitrate response of the miR5640/AtPPC3 pair on a time course using RT-qPCR. As shown in Figure 4C, AtPPC3 peak of induction by nitrate correlates with miR5640 repression by nitrate. The reduction of AtPPC3 levels over time also correlates with the de-repression of miR5640, suggesting that AtPPC3 levels are post-transcriptionally regulated by this miRNA in response to nitrate. Thus, miR5640/AtPPC3 represents a nitrate-responsive module that could be important for modulating carbon $/ \mathrm{N}$ balance for nitrate assimilation in Arabidopsis roots.

\section{Discussion}

High throughput sequencing approaches have become powerful tools to identify the transcriptome of Arabidopsis and other systems. Besides the ability to 
Table 2 Illumina sequencing identifies novel miRNAs

\begin{tabular}{|c|c|c|c|c|c|c|c|}
\hline miRNA & Chr & miRNA Start & miRNA End & Mature Sequence & miRNA* & miRNA previoulsy reported & miRNA located in \\
\hline miR5640 & $1(-)$ & 1653540 & 1653560 & AUGAGAGAAGGAAUUAGAUUC & YES & ath-miR5640 [47] & AT1G05570.1 intron \\
\hline ath-MIR472-5p & $1(-)$ & 4182266 & 4182286 & AUGGUCGAAGUAGGCAAAAUC & NO & Novel & ath-MIR472 stem loop \\
\hline ath-MIR8166 & $1(-)$ & 4525316 & 4525337 & AGAGAGUGUAGAAAGUUUCUCA & $\mathrm{NO}$ & Novel & Intergenic region AT1G13240-AT1G13245 \\
\hline miR5654-3p & $1(+)$ & 11786350 & 11786371 & GAAGAUGCUUUGGGAUUUAUUU & $\mathrm{NO}$ & miR5654-3p $[47,63]$ & AT1G32583.1, 5'UTR \\
\hline ath-MIR829-5p & $1(-)$ & 11834153 & 11834173 & ACUUUGAAGCUUUGAUUUGAA & YES & Novel & ath-MIR829 stem loop \\
\hline miR5014a & $1(+)$ & 24554009 & 24554029 & UGUUGUACAAAUUUAAGUGUA & YES & ath-miR5014a $[47,60]$ & AT1G65960.1 intron \\
\hline ath-MIR840-3p & $1(-)$ & 771385 & 771405 & UUGUUUAGGUCCCUUAGUUUC & YES & Novel & ath-MIR840 stem loop \\
\hline ath-MIR398a-3p & $2(+)$ & 1040948 & 1040968 & AAGGAGUGGCAUGUGAACACA & YES & Novel & ath-MIR398a stem loop \\
\hline ath-MIR8180 & $2(+)$ & 2063980 & 2063998 & UGCGGUGCGGGAGAAGUGC & $\mathrm{NO}$ & Novel & Intergenic region AT2G05580-AT2G05590 \\
\hline ath-MIR8175 & $2(+)$ & 3740938 & 3740957 & GAUCCCCGGCAACGGCGCCA & $\mathrm{NO}$ & Novel & Intergenic region AT2G09880-AT2G09890 \\
\hline ath-MIR396a-3p & $2(-)$ & 4142331 & 4142351 & GUUCAAUAAAGCUGUGGGAAG & YES & Novel & ath-MIR396a stem loop \\
\hline ath-MIR8168 & $2(+)$ & 5080690 & 5080710 & AGGUGCUGAGUGUGCUAGUGC & NO & Novel & Intergenic region AT2G12490-AT2G12500 \\
\hline ath-MIR5632-5p & $2(-)$ & 8392588 & 8392608 & UUGAUUCUCUUAUCCAACUGU & YES & Novel & ath-MIR5632 stem loop \\
\hline ath-MIR8167a & $2(+)$ & 8894985 & 8895006 & AGAUGUGGAGAUCGUGGGGAUG & NO & Novel & Intergenic region AT2G20620-AT2G20625 \\
\hline miR5995b & $2(-)$ & 10026977 & 10026997 & AAAGAUGCAGAUCAUAUGUCC & YES & ath-miR5995b [63]) & Intergenic region AT2G23540-AT2G23550 \\
\hline ath-MIR831-5p & $2(+)$ & 10247259 & 10247280 & AGAAGCGUACAAGGAGAUGAGG & $\mathrm{NO}$ & Novel & ath-MIR831 stem loop \\
\hline miR5637 & $2(-)$ & 12270195 & 12270216 & UAGAGGAAAAUAUAGAGUUGGG & NO & ath-miR5637 [47] & Intergenic region AT2G28620-AT2G28625 \\
\hline ath-MIR8170.1 & $2(+)$ & 14100020 & 14100040 & AUAGCAAAUCGAUAAGCAAUG & YES & Novel & AT2G33255.1 intron \\
\hline ath-MIR8170.2 & $2(+)$ & 14100079 & 14100099 & UUGCUUAAAGAUUUUCUAUGU & YES & Novel & AT2G33255.1 intron \\
\hline ath-MIR160a-3p & $2(+)$ & 16340342 & 16340362 & GCGUAUGAGGAGCCAUGCAUA & YES & Novel & ath-MIR160a stem loop \\
\hline ath-MIR8171 & $2(+)$ & 16890466 & 16890486 & AUAGGUGGGCCAGUGGUAGGA & $\mathrm{NO}$ & Novel & AT2G40440.1 intron \\
\hline ath-MIR166a-5p & $2(+)$ & 19176128 & 19176148 & GGACUGUUGUCUGGCUCGAGG & YES & Novel & ath-MIR166 stem loop \\
\hline ath-MIR408-5p & $2(+)$ & 19319866 & 19319886 & ACAGGGAACAAGCAGAGCAUG & YES & Novel & ath-MIR408 stem loop \\
\hline miR5650 & $2(+)$ & 19686959 & 19686979 & UUGUUUUGGAUCUUAGAUACA & YES & ath-miR5650 [47] & AT2G48140.1 intron \\
\hline miR173-5p & $3(+)$ & 8236161 & 8236182 & UUCGCUUGCAGAGAGAAAUCAC & YES & ath-miR173-5p [62,63] & ath-miR173-5p stem loop \\
\hline ath-MIR8169 & $3(+)$ & 8836359 & 8836379 & AUAGACAGAGUCACUCACAGA & $\mathrm{NO}$ & Novel & Intergenic region AT3G24340-AT3G24350 \\
\hline ath-MIR8183 & $3(-)$ & 11747799 & 11747819 & UUUAGUUGACGGAAUUGUGGC & $\mathrm{NO}$ & Novel & AT3G30110.1, pseudogene \\
\hline ath-MIR8165 & $3(-)$ & 16538510 & 16538530 & AAUGGAGGCAAGUGUGAAGGA & NO & Novel & Intergenic region AT3G45170-AT3G45180 \\
\hline ath-MIR8174 & $3(-)$ & 16589431 & 16589451 & AUGUGUAUAGGGAAGCUAAUC & NO & Novel & Intergenic region AT5G38460-AT5G38470 \\
\hline miR5651 & $3(+)$ & 17178489 & 17178509 & UUGUGCGGUUCAAAUAGUAAC & YES & ath-miR5651 [47] & Intergenic region AT3G46616-AT3G46620 \\
\hline ath-MIR8167b & $3(-)$ & 8894985 & 8895006 & AGAUGUGGAGAUCGUGGGGAUG & NO & Novel & Intergenic region AT3G47410-AT3G47420 \\
\hline ath-MIR8167c & $3(-)$ & 17469946 & 17469967 & AGAUGUGGAGAUCGUGGGGAUG & NO & Novel & Intergenic region AT3G50700-AT3G50710 \\
\hline miR5633 & $3(+)$ & 19544786 & 19544807 & AUGAUCAUCAGAAAACAGUGAU & $\mathrm{NO}$ & ath-miR5633 [47]) & Intergenic region AT3G52730-AT3G52740 \\
\hline ath-MIR393b-3p & $3(+)$ & 20691778 & 20691798 & AUCAUGCGAUCUCUUUGGAUU & YES & Novel & ath-MIR393 stem loop \\
\hline
\end{tabular}


Table 2 Illumina sequencing identifies novel miRNAs (Continued)

\begin{tabular}{|c|c|c|c|c|c|c|c|}
\hline ath-MIR8182 & $3(+)$ & 22678166 & 22678187 & UUGUGUUGCGUUUCUGUUGAUU & NO & Novel & AT3G61270.1, 5'UTR \\
\hline ath-MIR166b-5p & $3(+)$ & 22922212 & 22922232 & GGACUGUUGUCUGGCUCGAGG & YES & Novel & ath-MIR166 stem loop \\
\hline ath-MIR8172 & $4(-)$ & 7102572 & 7102592 & AUGGAUCAUCUAGAUGGAGAU & YES & Novel & Intergenic region AT4G11800-AT4G11810 \\
\hline ath-MIR8179 & $4(-)$ & 7161930 & 7161950 & UGACUGCAUUAACUUGAUCGU & NO & Novel & AT4G1192.1 intron \\
\hline ath-MIR8176 & $4(+)$ & 11795199 & 11795219 & GGCCGGUGGUCGCGAGAGGGA & $\mathrm{NO}$ & Novel & Intergenic region AT4G22320-AT4G22330 \\
\hline ath-MIR8178 & $4(+)$ & 18087285 & 18087305 & UAACAGAGUAAUUGUACAGUG & NO & Novel & AT4G38760.1 intron \\
\hline ath-MIR8184 & $5(-)$ & 3311974 & 3311994 & UUUGGUCUGAUUACGAAUGUA & NO & Novel & Intergenic region AT5G10504-AT5G10510 \\
\hline miR5629 & $5(+)$ & 3802933 & 3802954 & UUAGGGUAGUUAACGGAAGUUA & $\mathrm{NO}$ & ath-miR5629 [47] & Intergenic region AT5G11790-AT5G11800 \\
\hline ath-MIR865.2 & $5(+)$ & 5169992 & 5170011 & UCUGGGAUGAAUUUGGAUCU & $\mathrm{NO}$ & Novel & ath-MIR865 stem loop \\
\hline miR1888 & $5(+)$ & 7168879 & 7168899 & UAAGUUAAGAUUUGUGAAGAA & NO & ath-miR1888 [61,62] & AT5G21100.1 intron \\
\hline ath-MIR8173 & $5(-)$ & 7478572 & 7478592 & AUGUGCUGAUUCGAGGUGGGA & NO & Novel & Intergenic region AT5G22510-AT5G22520 \\
\hline ath-MIR8177 & $5(-)$ & 9362634 & 9362655 & GUGUGAUGAUGUGUCAUUUAUA & $\mathrm{NO}$ & Novel & Intergenic region AT5G26617-AT5G26620 \\
\hline miR5638b & $5(+)$ & 14100017 & 14100037 & ACAGUGGUCAUCUGGUGGGCU & $\mathrm{NO}$ & ath-miR5638b [47] & Intergenic region AT5G35945-AT5G35950 \\
\hline ath-MIR160c-3p & $5(-)$ & 19009095 & 19009115 & CGUACAAGGAGUCAAGCAUGA & YES & Novel & ath-MIR160c stem loop \\
\hline ath-MIR870-5p.1 & $5(-)$ & 21395592 & 21395612 & UUAGAAUGUGAUGCAAAACUU & $\mathrm{NO}$ & Novel & ath-MIR870 stem loop \\
\hline ath-MIR870-5p.2 & $5(-)$ & 21395604 & 21395624 & AAGAACAUCAAAUUAGAAUGU & $\mathrm{NO}$ & Novel & ath-MIR870 stem loop \\
\hline ath-MIR8181 & $5(-)$ & 21641289 & 21641308 & UGGGGGUGGGGGGGUGACAG & NO & Novel & AT5G5333.1, intron \\
\hline
\end{tabular}

Sequences from the lllumina libraries were queried for sequences representing putative new miRNAs with the miRCat program from the UEA sRNA toolkit. We show the genomic location and sequences of these miRNAs. Presence of reads corresponding to miRNA* are indicated (Yes or No). miRNAs that are not included in miRBase 17 but that have been cross-validated by other groups are indicated

The name of mature sequences derived from the same arm of known hairpin precursor were named with the suffix.1 or .2. If the sequences derive from the opposite arm from the previously annotated sequence, were named with the suffix $-5 p,-3 p$. 

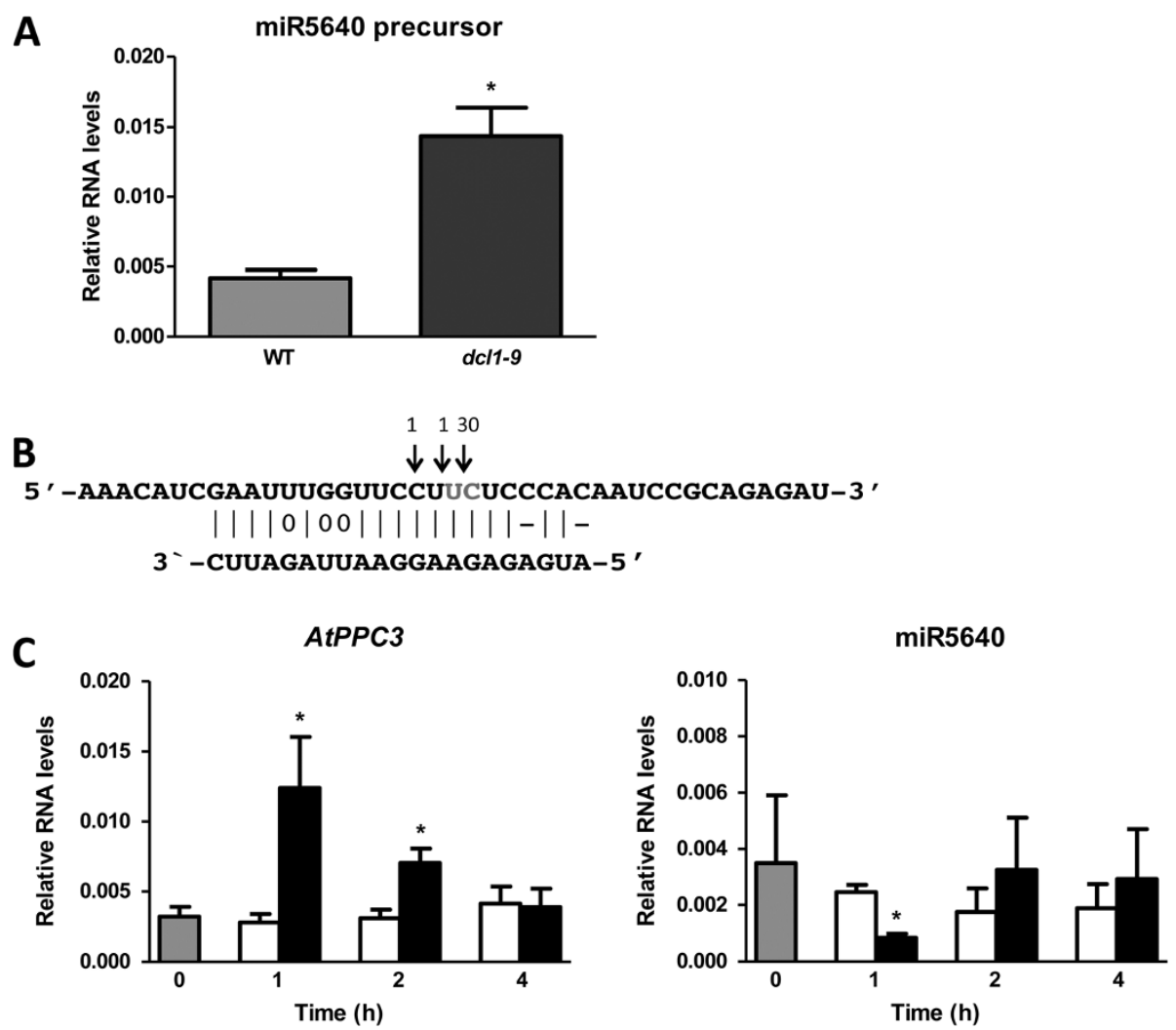

Figure 4 Illumina sequencing identifies a novel miRNA/TARGET module consisting of miR5640 and its target, AtPPC3. A. We analyzed the RNA levels of miR5640 predicted precursor using RT-qPCR in WT plants and in the dcl1-9 mutant. B. We used RLM-RACE to validate AtPPC3 as target of miR5640. The arrows show the numbers of colonies found with the cleavage product. $\mathbf{C}$. We determined the RNA levels of AtPPC3 and of mature miR5640 after 1, 2 and 4 hours of nitrate (black bars) or KCl (white bars) treatments. We show the results of three biological replicates and standard error.

profile novel genes expressed at low levels which could not be identified by traditional cloning and sequencing approaches, the high depth of sequencing obtained by these techniques allows for the absolute quantification of genes, and the comparison of gene expression under different experimental conditions [38,73,74]. Our high throughput sequencing results provided a detailed view of poly-A + RNAs and sRNAs expressed in Arabidopsis roots. We found that roots express a considerable portion of known protein coding genes and miRNA genes. However, most of these genes are expressed at low levels. These transcripts might represent cell specific transcripts whose expression is diluted when considering the whole root. Transcriptomics analysis of specific root cell types has shown that gene expression has an important cell-specific component that gives rise to functional diversification of cells $[52,53]$.

Even though the sequencing depth used to characterize the sRNA component did not allow for accurate quantitative estimates, we were able to discover novel miRNAs that have eluded previous efforts. Our bioinformatics analysis predicted 51 putative miRNAs expressed in roots under the experimental conditions. Most of these sequences were poorly expressed with less than 1 transcript per million transcripts. A recent publication that analyzes miRNA expressed in specific developmental zones and cell types of the root shows that 9 of these new miRNAs have cell or developmental zone specific expression [47] which can explain their low expression in the whole root samples. We were able to validate one of the predicted miRNAs, miR5640, as a putative miRNA expressed in roots. This miRNA is located inside intron 23 of the CALLOSE SYNTHASE 1 gene (CALS1, AT1G05570). Intronic miRNAs represent the majority of the miRNAs of animal systems but there are only a few examples in Arabidopsis [75,76]. Characterized intronic Arabidopsis miRNAs include miR162a and miR838 which are involved in the regulation of DCL1 [24,77,78]. However, analyzing our sequencing results, we found that the CALS1 transcript was not regulated by nitrate, thus miR5640 could have an independent nitrate-responsive promoter or primiR5640 processing to generate the mature miRNA could be a nitrate-regulated process.

We found miR5640 targeted the transcript that codes for AtPPC3, one of the four phosphoenolpyruvate carboxylase enzymes in Arabidopsis [79]. AtPPCs are important enzymes of carbon metabolism that catalyze the 
$\beta$-carboxylation of phosphoenolpyruvate to yield oxaloacetate. In C3 plants and algae, it has been shown that ATPPCs are important for the production of carbon skeletons for nitrogen assimilation [68,80,81]. Although there has been an extensive biochemical characterization of the AtPPCs enzymes in Arabidopsis, there are no reports of their function in $\mathrm{N}$ metabolism. AtPPC3 is a root specific AtPPC [82] and we found that it was nitrate-induced in our experiments, which is in agreement with the positive effect on nitrate assimilation predicted for this AtPPC. We also found evidence indicating that nitrate induction of AtPPC3 might depend on a miR5640-mediated post-transcriptional regulation of AtPPC3 levels in response to nitrate. Although we found AtPPC3 cleavage products that might be generated by miR5640 action over this transcript, we need further experiments to validate AtPPC3 as a miR5640 target (i.e. to analyze AtPPC3 levels in a miR5640 overexpressor plant), and to validate the role of this miRNA/TARGET module in nitrate assimilation in roots.

An advantage of using high throughput sequencing is the ability to interrogate gene expression without the representation bias present in microarray experiments. We discovered 40 protein-coding genes that have not been reported to be nitrate-responsive in previous transcriptomics analysis of Arabidopsis roots. Among them, we found highly responsive genes such as BT1 (At5g63160), a calmodulin-binding scaffold protein that acts redundantly with other BT proteins in female gametophyte development [83]. The closest homolog of BT1, BT2, has been reported to be responsive to multiple hormonal, stress and nutritional signals, including nitrate [84]. Interestingly, BT1 is only expressed when nitrate is supplied, suggesting that it might have a nitrate-specific function in roots. The AGG2 gene, one of the two genes encoding the gamma subunit of heterotrimeric $G$ protein was also induced by nitrate. Heterotrimeric $G$ protein in Arabidopsis has been involved in various developmental processes. In roots, it is involved in lateral root formation [85] and root apical meristem growth [86]. We have found that nitrate has an effect in primary and lateral root growth [37], thus nitrate regulation of $A G G 2$ might contribute to this response.

NATs are transcripts that fully or partially overlap with other transcripts. These pairs can mediate production of siRNAs to silence gene expression [87]. Additionally, NATs can modulate transcription, can affect mRNA stability and translation and can induce chromatin and DNA epigenetic changes [88]. Computational predictions have shown that the Arabidopsis genome potentially encodes sense-antisense transcript pairs representing approximately $7 \%$ of the protein coding genes [56]. We were able to identify 4 putative NATs of $>300 \mathrm{bp}$ in our sequencing data. One of these NATs was antisense to TCP23 gene and was induced by nitrate. TCP genes are transcription factors that promote growth and proliferation [89]. TCP23 is predicted to contain a chloroplast-targeting peptide, suggesting it might control transcription of chloroplast genes [90]. Although TCP23 has no described function, other class I TCP factors have been shown to be expressed in meristematic tissues and to control cell cycle genes such as PCNA and CYCB1;1 [91,92]. Thus, TCP23as induction by nitrate might repress TCP 23 expression, controlling meristematic activity of the primary root. However, further studies are needed to analyze TCP23as role over TCP23 expression on roots and on TCP23 regulation by nitrate.

\section{Conclusions}

In summary, the sequencing of small RNAs and mRNAs uncovered new genes, and enabled us to develop new hypotheses for nitrate regulation and coordination of carbon and $\mathrm{N}$ metabolism. A highlight is the discovery of a novel microRNA, miR5640 and its target, AtPPC3. The data suggest that the nitrate-responsive miRNA/target module might be involved in controlling carbon flux to assimilate nitrate into amino acids. These findings suggest that microRNAs can have metabolic regulatory functions, as well as previously described developmental functions $[37,44]$ in the nitrate response of Arabidopsis roots.

\section{Methods}

\section{Growth and treatment conditions}

Approximately 1,500 Arabidopsis seedlings were grown hydroponically on Phytatrays on MS-modified basal salt media without N (Phytotechnology Laboratories, M531) supplemented with $0.5 \mathrm{mM}$ ammonium succinate and $3 \mathrm{mM}$ sucrose under a photoperiod of $16 \mathrm{~h}$ of light and $8 \mathrm{~h}$ of darkness and a temperature of $22^{\circ} \mathrm{C}$ using a plant growth incubator (Percival Scientific, Inc.). After 2 weeks, plants were treated with $5 \mathrm{mM} \mathrm{KNO}_{3}$ or $5 \mathrm{mM} \mathrm{KCl}$ as control for 2 hours.

\section{Preparation of illumina libraries}

Total RNA from from nitrate-treated or control roots was extracted using Trizol $^{\circledR}$ (Invitrogen, cat. Number 15596026). For poly-A + libraries, poly-A + RNA was enriched using the Poly(A)Purist ${ }^{\mathrm{Tm}}$ MAG Kit (Ambion, cat, number AM1922M). Poly-A + RNA was decapped using tobacco acid pyrophosphatase and fragmented using RNA Fragmentation Reagents (Ambion, cat. Number AM8740). Low molecular weight RNA (<40 nt) was isolated from $100 \mu \mathrm{g}$ of total RNA by PAGE on a FlashPAGE ${ }^{\mathrm{mm}}$ fractionator (Ambion, cat. Number AM13100). For construction of the libraries, cloning linker (AMP-5'p $=5$ 'pCTG TAG GCA CCA TCA ATdideoxyC-3') was ligated to the 3' end of the RNA followed by purification of the ligation product on a $15 \%$ polyacrilamide/urea gel. The 3'-ligated 
product was ligated to the 5' Solexa linker (5'-rArCrA rCrUrC rUrUrU rCrCrC rUrArC rArCrG rArCrG rCrUrC rUrUrC rCrGrA rUrC-3'). RNA with ligated adaptors was reverse transcribed into DNA using Illumina specific primer (5'- CAA GCA GAA GAC GGC ATA CGA TTG ATG GTG CCT ACA G-3') and cDNA was then PCR amplified using this primer and a specific primer (5'-AAT GAT ACG GCG ACC ACC GAA CAC TGT TTC CCT ACA CGA CG-3'). The libraries were gel purified using the QIAquick gel extraction kit (QIAGEN, cat. Number 28704). Libraries were sequenced on the Illumina $1 \mathrm{G}$ Genome analyzer.

\section{Sequence analysis}

Raw sequences from the Illumina $1 G$ Genome analyzer in FASTQ format were analyzed with publicly available tools. Low quality reads were extracted with fastq quality filter by FASTX toolkit version 0.0 .13 (http://hannonlab. cshl.edu/fastx_toolkit/). The Phred quality score was set to 20, a probability of incorrect base call of 1 in 100. 3' adaptor sequences were trimmed from the Illumina reads, and then were mapped to the Arabidopsis TAIR10 genome using Novoalign version 2.05.17 (www.novocraft. com). Perfect match sequences having passed the quality control, polynucleotide filter, and size filter (between 18 and 28 nt for sRNA libraries and $\geq 18$ nt for poly-A + libraries) were selected for further analysis with custom made PERL scripts.

\section{Determination of differentially expressed genes}

To evaluate differential gene expression between $\mathrm{KNO}_{3}$ and $\mathrm{KCl}$ treated samples, we used sequence counts corresponding to sRNAs or annotated elements as input for the DESeq package version 1.1.6 [55] available from Bioconductor (www.bioconductor.org). This tool uses a negative binomial distribution model to test for differential gene expression [55]. We found correlation values of 0.91 and 0.96 for controls and treatments respectively for sRNA-seq and of 0.99 for controls and treatments for RNA-seq data. Replicates were used independently for statistical analysis of gene expression. We adjusted for multiple testing using FDR correction [93] and filtered genes whose expression changed with corrected p-values $\geq 0.05$.

\section{New miRNA and target predictions}

Quality filtered Illumina sequences were used as input for the MIRCAT tool [59], available at the University of East Anglia (UEA) sRNA toolkit (http://srna-tools.cmp. uea.ac.uk) using default parameters. To predict miRNA targets, we used the target prediction tool available from the UEA sRNA toolkit. The predicted targets, along with the putative cleavage site on these targets, were further validated using RNAhybrid version 2.1 [94].

\section{Predicting novel transcribed regions}

Novoalign alignments that did not overlap with annotated regions of the genome were pooled from all samples. Regions with continuous alignments in the same strand greater than 300 bp were identified as candidate novel transcribed regions.

\section{Gene expression analysis using RT-qPCR}

Gene expression analysis was carried out using the Brilliant $^{\oplus}$ SYBR $^{\oplus}$ Green QPCR Reagents on a Stratagene MX3000P qPCR system (Agilent) according to manufacturer's instructions. The RNA levels were normalized relative to the Clathrin adaptor complexes medium subunit family protein (At4g24550). Quantification of microRNA levels was carried out using the High-Specificity miRNA QRT-PCR Detection Kit from Stratagene on a Stratagene MX3000P qPCR system. The RNA levels were normalized relative to U6 snRNA (At3g14735). A list of RT-qPCR primers used in this work is provided in Additional file 12.

\section{RLM-RACE}

A modified procedure for RLM-RACE [70] was carried out using the GeneRacer ${ }^{\text {TM }}$ kit. The GeneRacer RNA Oligo adapter was directly ligated to $250 \mathrm{ng}$ of Poly-A + mRNA and the GeneRacer OligodT primer was used to synthesize first strand cDNA. This cDNA was subjected to a PCR amplification procedure with the GeneRacer 5'Primer and the GeneRacer 3'Primer to generate a pool of nongenespecific RACE products. Gene-specific 5'RACE reactions were performed with the GeneRacer $5^{\prime}$ Nested Primer and a reverse gene-specific primer. The expected size of the PCR amplicons was checked on a 3\% agarose gel. PCR products were cloned and sequenced to confirm predicted miRNA-mediated cleavage of the transcripts.

\section{Availability of supporting data}

The data sets supporting the results of this article are available in the NCBI GEO database [95] repository, under accession GSE44062.

\section{Additional files}

Additional file 1: Statistics of filtered sRNA and mRNA reads. Additional file 2: Global profiling of Illumina-sequenced sRNA. Additional file 3: Known miRNA and ta-siRNA expressed in roots. Additional file 4: mRNA reads that unambigoulsly match intergenic regions are located near $5^{\prime}$ and $3^{\prime}$ of annotated genes.

Additional file 5: Expression analysis of annotated elements of TAIR v.10.

Additional file 6: Gene expression distribution of genes represented in the ATH1 microarray in Illumina poly-A + libraries.

Additional file 7: Correlation between nitrate-regulated genes obtained by RNA-seq and Affymetrix ATH1 microarrays depends on Average gene coverage. 


\section{Additional file 8: Nitrate regulated genes determined using Illumina deep sequencing.}

Additional file 9: Deep sequencing of the Arabidopsis root poly-A + enriched fraction identifies new nitrate-regulated genes.

Additional file 10: Identification of putative new genes. Additional file 11: Prediction of putative targets for novel miRNA sequences.

Additional file 12: List of primers used for qRT-PCR.

\section{Competing interests}

The authors declare that they have no competing interests.

\section{Authors' contributions}

EAV participated in the design of the study, performed molecular biology experiments and statistical analyses and wrote the paper. TCM performed the computational analysis of the data, performed the experiments and wrote the paper. GK participated in the design of the study, performed experiments, analyzed the data and helped to draft the manuscript. MK performed computational analysis of the data and helped to draft the manuscript. MT generated the libraries for sequencing and helped to draft the manuscript. WRM participated in sequencing of the libraries. GMC participated in the design and coordination of the study and helped to draft the manuscript. RAG participated in the design and coordination of the study and wrote the paper. All authors read and approved the final manuscript.

\section{Acknowledgements}

This work was supported by International Early Career Scientist program from Howard Hughes Medical Institute to R.A.G., Fondo de Desarrollo de Areas Prioritarias (FONDAP) Center for Genome Regulation [15090007 to R.A.G.], Millennium Nucleus Center for Plant Functional Genomics [P10-062-F to R.A.G.], Fondo Nacional de Desarrollo Científico y Tecnológico [1100698 to R.A.G.], Comisión Nacional de Investigación Científica y Tecnológica-ANR program [ANR-007 to R.A.G.], the National Institutes of Health [GM032877 to G.M.C.] and National Science Foundation [MCB-0929338 to G.M.C.], Agence Nationale de la Recherche [NitroNet: ANR 11 PDOC 02001 to G.K.] and Centre National de la Recherche Scientifique [PEPS Bio math Info 2012-2013: SuperRegNet to G.K.]. E.A.V is supported by Proyecto de Inserción en la Academia (PSD74)

\section{Author details}

'FONDAP Center for Genome Regulation. Millennium Nucleus Center for Plant Functional Genomics, Departamento de Genética Molecular y Microbiología, Facultad de Ciencias Biológicas, Pontificia Universidad Católica de Chile, Santiago 8331010, Chile. ${ }^{2}$ Biochimie et Physiologie Moléculaire des Plantes, UMR 5004 CNRS/INRA/SupAgro-M/UM2, Institut de Biologie Intégrative des Plantes-Claude Grignon, Montpellier, France. ${ }^{3}$ Center for Genomics and Systems Biology, Department of Biology, New York University, New York, NY 10003, USA. ${ }^{4}$ Cold Spring Harbor Laboratory, New York, USA. ${ }^{5}$ Present address: School of Biological Sciences, The University of Queensland, St Lucia, Australia.

Received: 5 February 2013 Accepted: 10 June 2013 Published: 11 October 2013

\section{References}

1. Crawford NM: Nitrate: nutrient and signal for plant growth. Plant Cell 1995, 7:859-868.

2. Redinbaugh MG, Campbell WH: Higher plant responses to environmental nitrate. Physiol Plant 1991, 82:640-650.

3. Stitt M: Nitrate regulation of metabolism and growth. Curr Opin Plant Biol 1999, 2:178-186

4. Crawford NM, Glass ADM: Molecular and physiological aspects of nitrate uptake in plants. Trends Plant Sci 1998, 3:389-395.

5. Vidal EA, Gutiérrez RA: A systems view of nitrogen nutrient and metabolite responses in Arabidopsis. Curr Op Plant Biol 2008, 11:521-529.

6. Zhang $H$, Rong $H$, Pilbeam D: Signalling mechanisms underlying the morphological responses of the root system to nitrogen in Arabidopsis thaliana. J Exp Bot 2007, 58:2329-2338.
7. Forde BG, Walch-Liu P: Nitrate and glutamate as environmental cues for behavioural responses in plant roots. Plant Cell Environ 2009, 32:682-693.

8. Krouk G, Mirowski P, LeCun Y, Shasha D, Coruzzi G: Predictive network modeling of the high-resolution dynamic plant transcriptome in response to nitrate. Genome Biol 2010, 11:R123.

9. Wang $R$, Okamoto $M$, Xing $X$, Crawford NM: Microarray analysis of the nitrate response in Arabidopsis roots and shoots reveals over 1,000 rapidly responding genes and new linkages to glucose, trehalose-6phosphate, iron, and sulfate metabolism. Plant Physiol 2003, 132:556-567.

10. Wang R, Tischner R, Gutierrez RA, Hoffman M, Xing X, Chen M, Coruzzi G, Crawford NM: Genomic analysis of the nitrate response using a nitrate reductase-null mutant of Arabidopsis. Plant Physiol 2004, 136:2512-2522.

11. Wang $R$, Xing $X$, Crawford N: Nitrite acts as transcriptome signal at micromolar concentrations in Arabidopsis roots. Plant Physiol 2007, 145:1735-1745.

12. Wang $R$, Xing $X$, Wang $Y$, Tran A, Crawford NM: A genetic screen for nitrate regulatory mutants captures the nitrate transporter gene NRT1.1. Plant Physiol 2009, 151:472-478

13. Blencowe BJ, Ahmad S, Lee LJ: Current-generation high-throughput sequencing: deepening insights into mammalian transcriptomes. Genes Dev 2009, 23:1379-1386.

14. Malone J, Oliver B: Microarrays, deep sequencing and the true measure of the transcriptome. BMC Bio/ 2011, 9:34.

15. Marguerat S, Bähler J: RNA-seq: from technology to biology. Cell Mol Life Sci 2010, 67:569-579.

16. Morozova O, Hirst M, Marra MA: Applications of new sequencing technologies for transcriptome analysis. Annu Rev Genomics Hum Genet 2009, 10:135-151.

17. Mortazavi A, Williams BA, McCue K, Schaeffer L, Wold B: Mapping and quantifying mammalian transcriptomes by RNA-Seq. Nat Methods 2008, 5:621-628.

18. Wang Z: RNA-Seq: a revolutionary tool for transcriptomics. Nat Rev Genet 2009, 10:57-63.

19. Fahlgren N, Howell MD, Kasschau KD, Chapman EJ, Sullivan CM, Cumbie JS, Givan SA, Law TF, Grant SR, Dangl JL, Carrington JC: High-throughput sequencing of Arabidopsis microRNAs: evidence for frequent birth and death of miRNA genes. PLoS One 2007, 2:e219.

20. Henderson IR, Zhang X, Lu C, Johnson L, Meyers BC, Green PJ, Jacobsen SE: Dissecting Arabidopsis thaliana DICER function in small RNA processing gene silencing and DNA methylation patterning. Nat Genet 2006, 38:721-725.

21. Kasschau KD, Fahlgren N, Chapman EJ, Sullivan CM, Cumbie JS, Givan SA, Carrington JC: Genome-wide profiling and analysis of Arabidopsis siRNAs. PLOS Biol 2007, 5:e57.

22. Lu C, Kulkarni K, Souret FF, MuthuValliappan R, Tej SS, Poethig RS, Henderson IR, Jacobsen SE, Wang W, Green PJ, Meyers BC: MicroRNAs and other small RNAs enriched in the Arabidopsis RNA-dependent RNA polymerase-2 mutant. Genome Res 2006, 16:1276-1288.

23. Morin RD, O'Connor MD, Griffith M, Kuchenbauer F, Delaney A, Prabhu A-L, Zhao $Y$, McDonald $H$, Zeng $T$, Hirst $M$, et al: Application of massively parallel sequencing to microRNA profiling and discovery in human embryonic stem cells. Genome Res 2008, 18:610-621.

24. Rajagopalan $R$, Vaucheret $H$, Trejo J, Bartel DP: A diverse and evolutionarily fluid set of microRNAs in Arabidopsis thaliana. Genes Dev 2006, 20:3407-3425.

25. Huijser $P$, Schmid M: The control of developmental phase transitions in plants. Development 2011, 138:4117-4129.

26. Khan G, Declerck M, Sorin C, Hartmann C, Crespi M, Lelandais-Brière C MicroRNAs as regulators of root development and architecture. Plant Mol Biol 2011, 77:47-58.

27. Martin RC, Liu P-P, Goloviznina NA, Nonogaki H: microRNA, seeds, and Darwin?: diverse function of miRNA in seed biology and plant responses to stress. J Exp Bot 2010, 61:2229-2234.

28. Ruiz-Ferrer $\mathrm{V}$, Voinnet $\mathrm{O}$ : Roles of plant small RNAs in biotic stress responses. Annu Rev Plant Biol 2009, 60:485-510.

29. Sunkar R, Li Y-F, Jagadeeswaran G: Functions of microRNAs in plant stress responses. Trends Plant Sci 2012, 17:196-203.

30. Chiou T-J, Aung K, Lin S-I, Wu C-C, Chiang S-F, Su C-1: Regulation of phosphate homeostasis by microRNA in Arabidopsis. Plant Cell 2006, 18:412-421.

31. Fujii $\mathrm{H}$, Chiou T-J, Lin S-I, Aung K, Zhu J-K: A miRNA involved in phosphatestarvation response in Arabidopsis. Curr Biol 2005, 15:2038-2043.

32. Kawashima CG, Yoshimoto N, Maruyama-Nakashita A, Tsuchiya YN, Saito K, Takahashi H, Dalmay T: Sulphur starvation induces the expression of 
microRNA-395 and one of its target genes but in different cell types. Plant J 2009, 57:313-321.

33. Liang $G, H e H_{,}, Y u$ D: Identification of Nitrogen starvation-responsive microRNAs in Arabidopsis thaliana. PLoS One 2012, 7:e48951.

34. Pant BD, Musialak-Lange M, Nuc P, May P, Buhtz A, Kehr J, Walther D, Scheible W-R: Identification of nutrient-responsive Arabidopsis and Rapeseed microRNAs by comprehensive real-time polymerase chain reaction profiling and small RNA sequencing. Plant Physiol 2009, 150:1541-1555.

35. Zhao M, Ding H, Zhu J-K, Zhang F, Li W-X: Involvement of miR169 in the nitrogen-starvation responses in Arabidopsis. New Phytol 2011, 190:906-915.

36. Zhao M, Tai H, Sun S, Zhang F, XU Y, Li W-X: Cloning and characterization of Maize miRNAs involved in responses to nitrogen deficiency. PLoS One 2012, 7:e29669.

37. Vidal EA, Araus V, Lu C, Parry G, Green PJ, Coruzzi GM, Gutierrez RA: Nitrate-responsive miR393/AFB3 regulatory module controls root system architecture in Arabidopsis thaliana. Proc Natl Acad Sci USA 2010, 107:4477-4482.

38. Hsieh L-C, Lin S-I, Shih AC-C, Chen J-W, Lin W-Y, Tseng C-Y, Li W-H, Chiou T-J: Uncovering small RNA-mediated responses to phosphate-deficiency in Arabidopsis by deep sequencing. Plant Physiol 2009, 151:2120-2132.

39. Pantaleo V, Szittya G, Moxon S, Miozzi L, Moulton V, Dalmay T, Burgyan J: Identification of grapevine microRNAs and their targets using highthroughput sequencing and degradome analysis. Plant I 2010, 62:960-976.

40. Li F, Orban R, Baker B: SoMART: a web server for plant miRNA, tasiRNA and target gene analysis. Plant J 2012, 70:891-901.

41. Adai A, Johnson C, Mlotshwa S, Archer-Evans S, Manocha V, Vance V Sundaresan V: Computational prediction of miRNAs in Arabidopsis thaliana. Genome Res 2005, 15:78-91.

42. Jones-Rhoades MW, Bartel DP: Computational identification of plant microRNAs and their targets, including a stress-induced miRNA. Mol Cell 2004, 14:787-799.

43. Kozomara A, Griffiths-Jones S: miRBase: integrating microRNA annotation and deep-sequencing data. Nucleic Acids Res 2011, 39:D152-D157.

44. Gifford ML, Dean A, Gutierrez RA, Coruzzi GM, Birnbaum KD: Cell-specific nitrogen responses mediate developmental plasticity. Proc Natl Acad Sci USA 2008, 105:803-808.

45. Gutierrez RA, Lejay L, Dean A, Chiaromonte F, Shasha DE, Coruzzi GM: Qualitative network models and genome-wide expression data define carbon/nitrogen-responsive molecular machines in Arabidopsis. Genome Biol 2007, 8:R7.

46. Yang $X$, Zhang H, Li L: Global analysis of gene-level microRNA expression in Arabidopsis using deep sequencing data. Genomics 2011, 98:40-46.

47. Breakfield NW, Corcoran DL, Petricka JJ, Shen J, Sae-Seaw J, Rubio-Somoza I, Weigel D, Ohler U, Benfey PN: High-resolution experimental and computational profiling of tissue-specific known and novel miRNAs in Arabidopsis. Genome Res 2012, 22:163-176.

48. Bertone P, Stolc V, Royce TE, Rozowsky JS, Urban AE, Zhu X, Rinn JL, Tongprasit W, Samanta M, Weissman S, et al: Global identification of human transcribed sequences with genome tiling arrays. Science 2004, 306:2242-2246.

49. Johnson JM, Edwards S, Shoemaker D, Schadt EE: Dark matter in the genome: evidence of widespread transcription detected by microarray tiling experiments. Trends Genet 2005, 21:93-102.

50. Kapranov P, Cheng J, Dike S, Nix DA, Duttagupta R, Willingham AT, Stadler PF, Hertel J, Hackermüller J, Hofacker IL, et al: RNA maps reveal new RNA classes and a possible function for pervasive transcription. Science 2007, 316:1484-1488.

51. Khaitovich P, Kelso J, Franz H, Visagie J, Giger T, Joerchel S, Petzold E, Green $R E$, Lachmann M, Pääbo S: Functionality of intergenic transcription: an evolutionary comparison. PLoS Genet 2006, 2:e171

52. Birnbaum K, Shasha DE, Wang JY, Jung JW, Lambert GM, Galbraith DW, Benfey PN: A gene expression map of the Arabidopsis root. Science 2003, 302:1956-1960.

53. Brady SM, Orlando DA, Lee J-Y, Wang JY, Koch J, Dinneny JR, Mace D, Ohler U, Benfey PN: A high-resolution root spatiotemporal map reveals dominant expression patterns. Science 2007, 318:801-806.

54. Scheible WR, Morcuende R, Czechowski T, Fritz C, Osuna D, Palacios-Rojas N, Schindelasch D, Thimm O, Udvardi MK, Stitt M: Genome-wide reprogramming of primary and secondary metabolism, protein synthesis, cellular growth processes, and the regulatory infrastructure of Arabidopsis in response to nitrogen. Plant Physiol 2004, 136:2483-2499.
55. Anders $\mathrm{S}$, Huber W: Differential expression analysis for sequence count data. Genome Biol 2010, 11:R106.

56. Wang X-J, Gaasterland T, Chua N-H: Genome-wide prediction and identification of cis-natural antisense transcripts in Arabidopsis thaliana. Genome Biol 2005, 6:R30

57. Ghosh Z, Chakrabarti J, Mallick B: miRNomics-The bioinformatics of microRNA genes. Biochem Biophys Res Commun 2007, 363:6-11.

58. Meyers BC, Souret FF, Lu C, Green PJ: Sweating the small stuff: microRNA discovery in plants. Curr Opin Biotechnol 2006, 17:139-146.

59. Moxon S, Schwach F, Dalmay T, MacLean D, Studholme DJ, Moulton V: A toolkit for analysing large-scale plant small RNA datasets. Bioinformatics 2008, 24:2252-2253.

60. Borges F, Pereira PA, Slotkin RK, Martienssen RA, Becker JD: MicroRNA activity in the Arabidopsis male germline. J Exp Bot 2011, 62:1611-1620.

61. German MA, Pillay M, Jeong D-H, Hetawal A, Luo S, Janardhanan P, Kannan $V$, Rymarquis $L A$, Nobuta $K$, German $R$, et al: Global identification of microRNA-target RNA pairs by parallel analysis of RNA ends. Nat Biotech 2008, 26:941-946.

62. Moldovan D, Spriggs A, Yang J, Pogson BJ, Dennis ES, Wilson IW: Hypoxiaresponsive microRNAs and trans-acting small interfering RNAs in Arabidopsis. J Exp Bot 2010, 61:165-177.

63. Zhang B, Jin Z, Xie D: Global analysis of non-coding small RNAs in Arabidopsis in response to jasmonate treatment by deep sequencing technology. J Integr Plant Biol 2012, 54:73-86.

64. Sobkowiak L, Karlowski W, Jarmolowski A, Szweykowska-Kulinska Z: Non-canonical processing of Arabidopsis pri-miR319a/b/c generates additional microRNAs to target one RAP2.12 mRNA isoform. Front Plant Sci 2012, 3:46.

65. Zhang W, Gao S, Zhou X, Xia J, Chellappan P, Zhou X, Zhang X, Jin H: Multiple distinct small RNAs originate from the same microRNA precursors. Genome Biol 2010, 11:R81

66. Allen E, Xie Z, Gustafson AM, Carrington JC: microRNA-directed phasing during trans-acting siRNA biogenesis in plants. Cell 2005, 121:207-221.

67. Schwab R, Palatnik JF, Riester M, Schommer C, Schmid M, Weigel D: Specific effects of microRNAs on the plant transcriptome. Dev Cell 2005, 8:517-527.

68. Huppe HC, Turpin DH: Integration of carbon and nitrogen metabolism in plant and algal cells. Annu Rev Plant Physiol Plant Mol Biol 1994, 45:577-607.

69. Sunkar R, Zhu J-K: Novel and stress-regulated microRNAs and other small RNAs from Arabidopsis. Plant Cell 2004, 16:2001-2019.

70. Llave C, Xie Z, Kasschau KD, Carrington JC: Cleavage of scarecrow-like mRNA targets directed by a class of Arabidopsis miRNA. Science 2002, 297:2053-2056.

71. Brodersen P, Voinnet O: The diversity of RNA silencing pathways in plants. Trends Genet 2006, 22:268-280

72. Kidner CA, Martienssen RA: The developmental role of microRNA in plants. Curr Op Plant Biol 2005, 8:38-44.

73. Lelandais-Briere C, Naya L, Sallet E, Calenge F, Frugier F, Hartmann C, Gouzy J, Crespi M: Genome-wide medicago truncatula small RNA analysis revealed novel microRNAs and isoforms differentially regulated in roots and nodules. Plant Cell 2009, 21:2780-2796.

74. Zhang J, Xu Y, Huan Q, Chong K: Deep sequencing of Brachypodium small RNAs at the global genome level identifies microRNAs involved in cold stress response. BMC Genomics 2009, 10:449.

75. Brown JWS, Marshall DF, Echeverria M: Intronic noncoding RNAs and splicing. Trends Plant Sci 2008, 13:335-342

76. Meng Y, Shao C: Large-scale identification of mirtrons in Arabidopsis and Rice. Plos One 2012, 7:e31163.

77. Xie Z, Kasschau KD, Carrington JC: Negative feedback regulation of Dicer-Like1 in Arabidopsis by microRNA-guided mRNA degradation. Curr Biol 2003, 13:784-789.

78. Kim YK, Kim VN: Processing of intronic microRNAs. EMBO J 2007, 26:775-783.

79. Sanchez R, Cejudo FJ: Identification and expression analysis of a gene encoding a bacterial-type phosphoenolpyruvate carboxylase from Arabidopsis and Rice. Plant Phys 2003, 132:949-957.

80. Podestá FE, Plaxton WC: Regulation of cytosolic carbon metabolism in germinating Ricinus communis cotyledons. Planta 1994, 194:381-387.

81. Scheible WR, Krapp A, Stitt M: Reciprocal diurnal changes of phosphoenolpyruvate carboxylase expression and cytosolic pyruvate kinase, citrate synthase and NADP-isocitrate dehydrogenase expression regulate organic acid metabolism during nitrate assimilation in tobacco leaves. Plant Cell Environ 2000, 23:1155-1167. 
82. Sánchez R, Flores A, Cejudo FJ: Arabidopsis phosphoenolpyruvate carboxylase genes encode immunologically unrelated polypeptides and are differentially expressed in response to drought and salt stress. Planta 2006, 223:901-909.

83. Robert HS, Quint A, Brand D, Vivian-Smith A, Offringa R: BTB and TAZ domain scaffold proteins perform a crucial function in Arabidopsis development. Plant J 2009, 58:109-121.

84. Mandadi KK, Misra A, Ren S, McKnight TD: BT2, a BTB protein, mediates multiple responses to nutrients, stresses, and hormones in Arabidopsis. Plant Phys 2009, 150:1930-1939.

85. Ullah H, Chen J-G, Temple B, Boyes DC, Alonso JM, Davis KR, Ecker JR, Jones AM: The $\beta$-subunit of the Arabidopsis $G$ protein negatively regulates auxin-induced cell division and affects multiple developmental processes. Plant Cell 2003, 15:393-409.

86. Chen J-G, Gao Y, Jones AM: Differential roles of Arabidopsis heterotrimeric G-protein subunits in modulating cell division in roots. Plant Physiol 2006, 141:887-897.

87. Borsani O, Zhu J, Verslues PE, Sunkar R, Zhu J-K: Endogenous siRNAs derived from a pair of natural cis-antisense transcripts regulate salt tolerance in Arabidopsis. Cell 2005, 123:1279-1291.

88. Faghihi MA, Wahlestedt C: Regulatory roles of natural antisense transcripts. Nat Rev Mol Cell Biol 2009, 10:637-643.

89. Martín-Trillo M, Cubas P: TCP genes: a family snapshot ten years later. Trends Plant Sci 2010, 15:31-39.

90. Wagner R, Pfannschmidt T: Eukaryotic transcription factors in plastids Bioinformatic assessment and implications for the evolution of gene expression machineries in plants. Gene 2006, 381:62-70.

91. Kosugi S, Ohashi Y: PCF1 and PCF2 specifically bind to cis elements in the rice proliferating cell nuclear antigen gene. Plant Cell 1997, 9:1607-1619.

92. Li C, Potuschak T, Colón-Carmona A, Gutiérrez RA, Doerner P: Arabidopsis TCP20 links regulation of growth and cell division control pathways. Proc Natl Acad Sci USA 2005, 102:12978-12983.

93. Irizarry RA, Hobbs B, Collin F, Beazer-Barclay YD, Antonellis KJ, Scherf U Speed TP: Exploration, normalization, and summaries of high density oligonucleotide array probe level data. Biostatistics 2003, 4:249-264.

94. Rehmsmeier M, Steffen P, Höchsmann M, Giegerich R: Fast and effective prediction of microRNA/target duplexes. RNA 2004, 10:1507-1517.

95. Edgar R, Domrachev M, Lash AE: Gene Expression Omnibus: NCBI gene expression and hybridization array data repository. Nucleic Acids Res 2002, 30:207-210.

doi:10.1186/1471-2164-14-701

Cite this article as: Vidal et al.: Integrated RNA-seq and sRNA-seq analysis identifies novel nitrate-responsive genes in Arabidopsis thaliana roots. BMC Genomics 2013 14:701.

\section{Submit your next manuscript to BioMed Central and take full advantage of:}

- Convenient online submission

- Thorough peer review

- No space constraints or color figure charges

- Immediate publication on acceptance

- Inclusion in PubMed, CAS, Scopus and Google Scholar

- Research which is freely available for redistribution 